\title{
JAVANESE TRADITIONAL ART-DANCE AS THE IMPLEMENTATION OF CHARACTER EDUCATION OF CHILDREN TO SUPPORT CHILD FRIENDLY SCHOOL
}

\author{
Siti Supeni \\ FKIP Unisri Surakarta \\ siti.supeni15.unisri@gmail.com
}

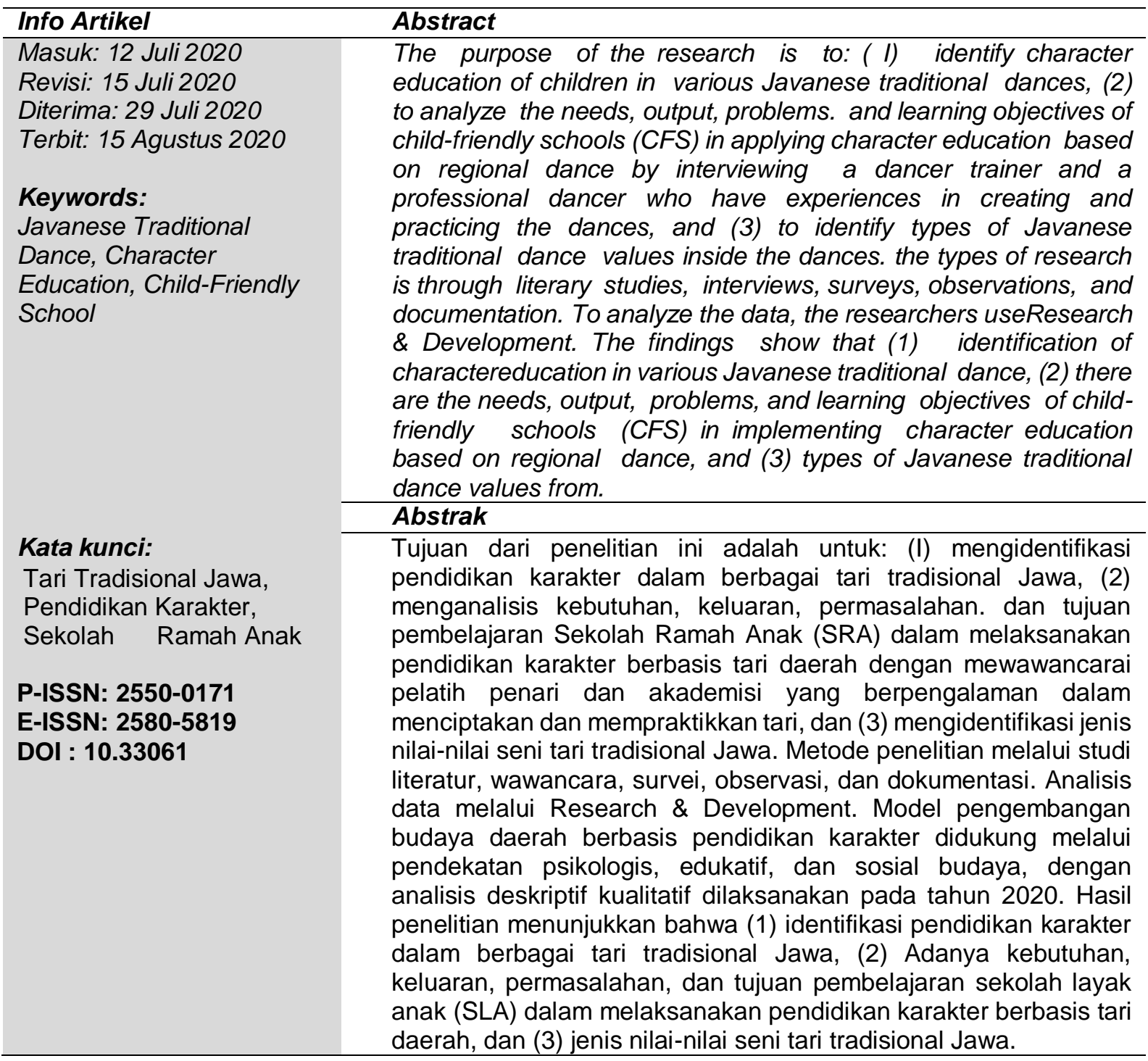

\section{PENDAHULUAN}

Indonesia memiliki banyak sekali tarian tradisional yang menunjukkan penghormatan terhadap budayanya sendiri, dilestarikan sebagai warisan lokal dan mengadopsinya untuk mencerdaskan masyarakat. Tari Seblang adalah salah satu tarian tradisional dari Banyuwangi, Indonesia yang bertujuan untuk meningkatkan kesejahteraan masyarakat, melestarikan kesuburan tanah dan meyakinkan keberhasilan tanaman berikutnya (Wessing, 1999). Seni pertunjukan Sahita memiliki pelajaran untuk menyampaikan kesulitan berbicara dalam kehidupan sehari-hari dan untuk menyatakan kritik dengan gaya humor. Pertunjukannya berupa kesenian tradisional yang dilengkapi dengan cita rasa kontemporer (Ardhiani, 2016). Menggambarkan bagaimana kesurupan dalam tari tradisional Jathilan dipahami dan dibawakan sesuai dengan ketersediaan literatur, 1 "catatan tangan praktisi, banyak pertunjukan yang diamati dan didokumentasikan, dipertimbangkan dalam konteks kepercayaan Jawa dan implementasinya. (Rapoport, 2018). 
Ada banyak kajian dan artikel untuk membina, melestarikan, dan membahas tarian tradisional. Irianto (2016) melakukan penelitian untuk mendeskripsikan strategi yang diadaptasi untuk memelihara dan membina tari Adat Jawa Jathilan karena dilihat dari identitas budaya yang memiliki peran sosial dan ritual tertentu. Arjo (1989) membahas peran penari wanita di Sunda, Jawa Barat, Indonesia di mana ia menampilkan peran wanita dari tahun 1891 hingga sekarang, yaitu tari Ronggeng. Christensen (2013) melakukan penelitian untuk mendeskripsikan argumennya tentang tari Jathilan di Yogyakarta, Indonesia dalam melakukan kerja lapangan di pulau Jawa. Saputra, Supriyadi, \& Demartoto (2019) melakukan penelitian untuk mempelajari reproduksi wisata budaya kreatif di Sanggar Tari Soeryo Soemirat Mangkunegaran dan hasil reproduksi pariwisata yang berlangsung di Sanggar Soerya Soemirat dan pertunjukan tari 24 jam. Dewi (2018) melakukan penelitian untuk mengungkapkan tradisi panji (tari Jaranan dan Wayang Timplong) dalam seni pertunjukan di Jawa Timur dan berusaha mengungkap gerak tari yang berfungsi sebagai hiburan, bukan upacara lagi, meskipun Wayang Timplong masih ada. sebuah fungsi dalam upacara.

Inovasi tari tradisional berperan penting untuk melestarikan tari dan mengembangkannya agar anak muda tertarik untuk belajar. Sawitri, Sudardi, Abdullah, \& Chaya (2016) melakukan penelitian untuk mengungkapkan inovasi bedhaya AngonAngin, bedhaya Silikon (misalnya seragam, musik, properti) oleh seniman dari tari keramat Bedaya Jawa untuk tujuan pasar. Slamet (2019) belajar untuk memberikan pengetahuan dan pemahaman kepada masyarakat luas tentang koreografi pola tari Jaranan Temanggungan untuk pengembangan lebih lanjut dan menciptakan pola-pola tari baru yang membentuk tari tersebut. Selanjutnya, Wisang (2019) melakukan penelitian tentang ko-modifikasi tari Jaranan Turangga Yakso karena perkembangan pariwisata di wilayah Trenggalek, Indonesia. Selain itu, tari sebagai seni budaya Jawa berpotensi untuk mengembangkan pendidikan karakter di Surakarta, Denpasar, dan Jakarta Barat untuk mewujudkan kota ramah anak (Supeni, Nurati, Sufa, \& Jumintono, 2019).

Mengadopsi tarian daerah sebagai bagian dari materi pendidikan baik di dalam maupun di luar sekolah adalah untuk melestarikan budaya lokal dan mendidik peserta didik dengan budaya masa lalu yang memiliki pelajaran positif. Penggunaan nilai-nilai Reog (misalnya sosial dan agama) di sekolah menengah kejuruan diimplementasikan dalam bentuk pertunjukan Reog siswa (Ambarwangi \& Suharto, 2014). Tarian tradisional Maena dari Pulau Nias biasanya untuk upacara pernikahan dan penyambutan, juga untuk pendidikan bencana yang berkolaborasi untuk menyemangati masyarakat tentang bencana (Shoji, Takafuji, \& Harada, 2020). Giyartini (2018) mengkaji pembentukan model wisata pendidikan anak dengan mendesain ulang kemasan tari kreatif berbasis permainan tradisional tanpa meninggalkan nilai-nilai sehingga dapat meningkatkan kecerdasan dan kreativitas anak. Perumusan tari Tuping di SMA meliputi tujuan, materi, metode, model, media, dan evaluasi (Marsim, Mulyanto, \& Sudiyanto, 2019). Malarsih (2016) melakukan penelitian untuk merealisasikan media tari sebagai sarana pendidikan dalam kurikulum sekolah dan hasilnya tari telah berhasil mendorong siswa menjadi lebih aktif dan kreatif. Rosmiati (2018) mengkaji bagaimana strategi pembelajaran dalam pembinaan karakter nasionalis dengan menggunakan lagu dan permainan tradisional dan salah satunya Hasilnya, tari tari nasional dijadikan kegiatan ekstrakurikuler

\section{TINJAUAN PUSTAKA}

Tarian tradisional Jawa dijalankan dengan alat-alat pendukung karena era digital yang memudahkan para penari berlatih. (Sutyasadi \& Suharti, 2010) mempelajari penggunaan software Computer Aided Instruction (iCAI) yang interaktif untuk membantu dan menemani siswa menari, meskipun tidak sebagai pengganti instruktur tari dan 
hasilnya adalah mereka dapat melakukan latihan tari sendiri di sanggar dan mendapatkan masukan dari software. Alfianti, Pratiwi, \& Suyatno (2019) melakukan penelitian tentang parameter panggung akustik pada pertunjukan tari tradisional Jawa berdasarkan parameter akustik optimal gamelan Jawa. Alhasil, tempat maksimal pemain gamelan ada di pojok depan panggung. Nurindiyani, Pramadihanto, \& Afifah (2019) mempelajari penggunaan teknik motion capture dari penari asli tentang membangun pengetahuan untuk pemodelan 3D gerak tari Jawa. Hasil penelitian menunjukkan bahwa pembuatan kerangka model 3D dan perolehan data gerak tubuh dengan menggunakan motion capture dapat menjadi media interaktif pembelajaran tari tradisional Jawa.

Tarian tradisional Jawa memiliki nilai estetika yang menunjukkan ciri khas dan ciri utamanya. Jazuli (2015) mempelajari estetika tari Prajuritan di Kabupaten Semarang, Jawa Tengah, 151 Indonesia dan ia menemukan bahwa estetika tari tersebut terletak pada koreografi tari dan budaya. Sistem nilai yang tumbuh dan berkembang di kelompok Kabupaten Semarang. Setyaningrum, Asma, \& Indriyani (2018) melakukan penelitian untuk mengetahui nilai-nilai estetika dalam bentuk, isi, dan pementasan tari Gandaria di Kabupaten Rembang, Jawa Tengah, Indonesia. Alhasil, estetika tari dapat dilihat dari bentuk berbagai gerak, musik pengiring, tata rias dan tata busana, tata cahaya, tata suara, dan tempat), isi (ide, suasana, dan pesan yang mengandung nilai-nilai. kebersamaan, asosiasi, dan moralitas), dan kinerja (bakat, keterampilan, sarana / media).

Kajian tentang peran gender berperan penting untuk mengetahui posisi dan kontribusinya laki-laki dan / atau perempuan terhadap tari. Prihatini, Iswidayati, \& Hartono (2018) melakukan penelitian untuk mendeskripsikan pertunjukan tari Adaninggar-Kelaswara, mengidentifikasi peran perempuan dalam tari, dan mengkomunikasikan pesan pragmatis melalui tari tersebut. Hasil penelitian menunjukkan bahwa tari berkaitan dengan cara hidup dan nilai-nilai kepribadian perempuan Jawa. Okado (2011) meneliti tentang ekspresi kinerja lintas gender dalam drama tari tradisional Jawa Langendriyan ditinjau dari penampil, gerak, kostum, dan lagu. Hasil penelitian menunjukkan bahwa tari menantang masyarakat nonns dan hierarki yang mapan; Oleh karena itu ada gerakan untuk menemukan kembali nilai ekspresi lintas gender dalam tarian tersebut.

Berbagai kajian tentang nilai-nilai atau hikmah dari seni tari Jawa memberikan suatu substansi yang berharga yang dapat diperoleh seseorang bagi dirinya dan orang lain. Meinal \& Rahmawati (2016) mempelajari bagaimana masyarakat Yogyakarta mewariskan tari Srimpi dari generasi ke generasi dan ternyata tarian tersebut mengandung berbagai nilai seperti Regenerasi, Pendidikan, Adaptasi, Ekonomi, Kebanggaan, Eksistensi dan Ikatan Emosional. Denok, Jazuli, Rohindi, \& Suminto (2018) melakukan penelitian untuk menyampaikan bahwa tari Nawung Sekar dapat mengajarkan nilai kemanusiaan kepada digital nativesg enerasi.

Hasil penelitian menunjukkan bahwa tari dapat diadopsi sebagai media untuk mengajarkan nilai kepada generasi karena dapat membentuk karakter manusia. Susanti, Miftahuddin, \& Kurniawan (2019) melakukan penelitian untuk mengetahui nilai-nilai religi dalam tari Kuda Lumping. Hasil penelitian menunjukkan bahwa nilai-nilai tersebut ditemukan sebelum pertunjukan tari (Doa sarean) yang berlangsung di Punden untuk meminta uang kepada penjaga di Punden. Kusnadi, Ardhana, Setyosari, \& Efendi (2017) melakukan penelitian untuk mengetahui apakah strategi pembelajaran eksperiensial lebih efektif daripada strategi pembelajaran langsung dalam mengembangkan apresiasi siswa terhadap bahasa Jawa klasik. Hasilnya, pembelajaran berdasarkan pengalaman jauh lebih unggul daripada pengajaran langsung karena pengalaman nyata siswa dalam memperoleh ilmu dan berinteraksi dengan tarian klasik terbukti bermakna bagi mereka. 


\section{METODE PENELITIAN}

Tujuan dari penelitian ini adalah untuk: (1) mengidentifikasi pendidikan karakter dalam berbagai tari tradisional Jawa, (2) menganalisis kebutuhan, keluaran, masalah, dan tujuan pembelajaran Sekolah Ramah Anak (CFS) dalam melaksanakan pendidikan karakter berbasis tari daerah, dan (3) mengidentifikasi jenis nilai-nilai seni tari tradisional Jawa.

\section{a) Sampel dan Pengumpulan Data}

Teknik pengumpulan data dalam penelitian ini meliputi: wawancara dengan narasumber terkait dengan objek penelitian, pencatatan data berbagai aspek terkait Model Pengembangan Karakter Tari Daerah Berbasis Tari Daerah Mendukung Sekolah Ramah Anak (SRA) di Kota Surakarta, pembelajaran dan pembelajaran. mengkaji literatur yang dapat memberikan informasi untuk mendukung penelitian ini, dan pendokumentasian melalui pemotretan sumber data berupa kegiatan tari daerah yang dilakukan oleh anak-anak di kota Surakarta.

\section{b) Menganalisis Data}

Analisis dalam penelitian ini menekankan pada penerapan dengan menggunakan pendekatan budaya. Analisis interaksi dilakukan untuk menganalisis data kualitatif dari hasil pengumpulan data empiris untuk mendapatkan hasil yang akurat dari klasifikasi melalui identifikasi dan identifikasi.

\section{PEMBAHASAN}

Hasil dari Bergabungnya "KeinbangJoyo dan Galeri Tari" dan Anak-anak yang Menghadapi Galeri Penulis mewawancarai Bapak AB selaku pemilik sekaligus pelatih tari Rumah Seni dan Tari Kembang Joyo yang mengajari siswa-siswa Sekolah Dasar tentang hasil bergabung dengan rumahnya, sebagai berikut: Ada empat keluaran. Mereka dapat menampilkan tari di luar sanggar atas undangan dari instansi yang mengundang mereka, di Universitas Slamet Riyadi Surakarta pada acara Dies Natalis, dan kegiatan Wisuda; mampu menari di Kabupaten Karanganyar sebagai pertunjukan untuk wisatawan domestik / mancanegara; mampu menampilkan seni pada perayaan hari kemerdekaan Republik Indonesia setiap tahun, menghibur masyarakat di desanya (Sanggar Seni); dan mempertunjukkan kesenian Rutin setiap empat puluh hari (selapanan) pada hari sabtu paing, dalam memperingati hari jawa didirikan "Sanggar Seni Bunga Joyo". Selain itu, saya mendapatkan berbagai kendala dalam melatih dan mengelola sebuah tarian. Saya menemukan keterbatasan fasilitas yang tidak memadai (ruang latihan, alat musik gamelan); Tidak dapat berjalan maksimal karena keterbatasan jumlah trainee, trainer dan dana yang terbatas; dan ketersediaan kostum penari secara umum yang harus dikenakan pada saat pentas tari dilakukan telah mendapatkan 200 kostum dari Menteri Pendidikan dan Kebudayaan.

Bapak AB merancang beberapa hasil yang harus dicapai oleh siswanya. Mampu perform di luar galeri merupakan salah satu output untuk menunjukkan eksistensi galeri, khususnya pelajar (penari). Ini juga sebagai media untuk melatih kemajuan tarian; Oleh karena itu dia dapat melakukan tindakan lebih lanjut untuk menghadapi kemajuan, mis. memberikan perlakuan tambahan pada tari untuk menyelesaikan masalah pada gerakan tertentu. Penonton tari juga dapat menikmati tarian dari gerakan dan makna filosofis di balik tarian tersebut sebagai hiburan dan pelajaran bagi mereka. Mampu menari di tingkat universitas, mis. Wisuda atau hari jadi institusi merupakan suatu kebanggaan yang berarti mahasiswa mendapatkan kepercayaan dari masyarakat tentang ketrampilan menari. Tampil dalam perayaan kemerdekaan Indonesia ini juga menjadi salah satu target dirinya dan murid-muridnya untuk menunjukkan kearifan lokal yang harus dilestarikan dan menunjukkan bahwa kearifan lokal (tari) masih ada dan harus dijaga dan dilestarikan oleh semua. 
Selain itu, Pak AB mendapat kendala dalam melestarikan galeri seni. Sarana yang kurang memadai untuk menunjang latihan menari jangan sampai terjadi (ruang latihan, alat musik gamelan) karena jumlah wisatawan yang banyak. Sangat menarik untuk menghibur wisatawan yang dapat mendukung keuangan lembaga, karena dukungan keuangan yang tidak mencukupi untuk memfasilitasi kegiatan pelatih dan peserta pelatihan; Oleh karena itu ia perlu berpikir untuk mencari berbagai solusi. Jumlah trainee dan trainer yang bisa berlatih menari perlu ditingkatkan. Memiliki 200 kostum perlu dipertahankan dengan berlatih secara rutin.

\section{Cara Menarik Minat Mahasiswa dan Rencana Kerja Pengembangan Galeri Seni}

Penulis juga meminta kepada Pak $A B$ untuk menceritakan tentang caranya menarik minat dan mengembangkan siswa rumah-rumahnya, sebagai berikut: Saya punya solusi untuk menarik minat siswa. Pentas seni sebulan sekali (Sabtu Paing) untuk memotivasi rajin berlatih, penjelasan tentang makna i'dance "dilakukan dalam membangun karakter disiplin, bersosialisasi, berkomunikasi secara sopan dengan guru pelatih dan dengan teman-temannya. media sosial melalui "Joyo Flower Art Studio", baik dari pelajar / anak-anak, orang tua, Pemerintah, dan masyarakat yang juga menikmati pertunjukan seni pertunjukan dari "Joyo Flower Art Studio". Lalu, saya punya banyak rencana untuk membina kesenian tersebut. Sanggar yang bekerja sama dengan ISI Surakarta dalam memberikan bantuan profesional, Kolaborasi pelatih dengan Dosen Seni PGSD UNISRI Surakarta; menyediakan fasilitas yang memadai, membuat renovasi panggung sederhana untuk pertunjukan tari, dan mediasi dengan galeri seni lain untuk berkolaborasi menjadikan seni sebagai pertunjukan untuk pengunjung turis.

Pak $A B$ punya ide untuk membangkitkan minat siswa tentang latihan tari. Jadwalnya berlatih menari sebulan sekali sangat bermanfaat untuk melatih anakanaknya terus menari. Kegiatan tersebut tidak hanya sekedar melatih menari, tetapi juga memberikan teori teoritis tentang filosofi tari yang dipraktekkan untuk memahami hakikat dan membangun komunikasi antara siswa dengan dirinya serta membentuk karakter sosial pada saat latihan menari. Pemanfaatan media sosial yang memuat penampilan dari siswa / anak, orang tua, pemerintah, dan masyarakat cukup berhasil mendorong siswa untuk berlatih melestarikan tari. Media juga mempromosikan secara positif berbagai macam tarian sehingga calon siswa dapat memilih jenis tarian yang ingin mereka praktikkan sesuai dengan minatnya.

Pak $A B$ punya banyak rencana untuk mengembangkan studio seninya. la bekerjasama dengan beberapa instansi terkait, mis. Institut Seni Indonesia mendapatkan beberapa tenaga profesional untuk melatih murid-muridnya dan program guru sekolah dasar yang menyediakan tenaga pengajar untuk bergabung menjadi pelatih. la menyediakan fasilitas standar untuk latihan menari (misalnya seragam) dan bangunan untuk difasilitasi (misalnya kamar istirahat dan panggung untuk pertunjukan tari). Bekerja sama dengan galeri seni lain dalam merancang program seni untuk memberikan pelayanan kepada wisatawan adalah memperkuat keberadaan galeri dan saling memberikan kerjasama dalam berbagi ide dan pengalaman dalam memberikan pelayanan kepada wisatawan.

\section{Macam-Macam Nilai Tarian Tradisional Jawa}

Makna gerak tari dalam internalisasi pendidikan karakter berbasis tari budaya daerah (Jawa), makna gerak telah menjadi bahan pemikiran para ahli tari sejak jaman dahulu kala. Bahkan di India itu ditulis secara sistematis lebih dari 2000 tahun yang lalu. Mengenai karakter baru tari yang dipikirkan oleh para koreografer Barat pada abad ke20 (Soedarsono, 1972: 36), karakter gerak dapat dihadirkan dari tubuh manusia. Karakter gerak ini bervariasi tergantung pada bagian mana dari tubuh manusia yang diekspresikannya. Bagian atas adalah bagian yang memiliki karakter intelektual dan 
spiritual yang terletak di dada ke atas. Ekspresi intelektual atau spiritual akan lebih berhasil jika dipusatkan di atas. Perasaan yang penuh dengan perasaan terletak di tengah-tengah yaitu di antara bahu hingga pinggang. Bagian tengah ini, memiliki perasaan yang penuh dengan perasaan. Emosi penari dapat dituangkan melalui bagian tengah ini, sedangkan bagian bawah terletak di antara pinggang dan lantai. Bagian bawah merupakan bagian vital yang penuh dengan daya hidup (La Meri Soedarsono 1972: 38). Jika dilihat lebih jauh pada garis-garis geraknya, secara garis besar gerakan tari dapat dibagi menjadi dua bagian, yaitu gerak simetris dan gerak asimetris, sebagai berikut:

(1) Garis simetris bersifat sederhana, kokoh, kalem tetapi akan membosankan jika digunakan juga sering. (Karakter yang simpel, kokoh, tenang)

(2) Garis asimetris memiliki karakter yang kurang kokoh, tetapi dinamis dan menarik. Dengan garis gerak yang memiliki perbedaan karakter, maka seorang koreografer agar karyanya tetap menarik disarankan untuk menggunakan garis yang lebih asimetris. (karakter dinamis, dan menarik).

(3) Garis-garis gerak juga dapat dibedakan menjadi dua jenis, yaitu garis silang atau akan bertemu dan garis atau arah terpisah. Karakter gerak pada garis silang penuh energi dan vitalitas, sedangkan garis terpisah bersifat halus dan lembut.

(4) Setiap gerakan yang dilakukan penari akan memberikan kesan tersendiri bagi penontonnya. (membuat Anda merasa senang / senang karena bisa menikmati seni keindahan dari gerakan-gerakan tari).

(5) Arti gerak, terintegrasi dalam gerak; Misalnya jika seorang penari menggambarkan tangisan, ia akan menggunakan gerakan bermakna dengan menutupi wajahnya dan mengecilkan tubuhnya. (memaknai rasa iba, empati terhadap makna cerita yang ditarikan, hal ini akan mengasah ketajaman jiwa (olah rasa, olah jiwa). Dengan demikian penari akan berhasil mengekspresikan gerak tangis atau kesedihan bila memadukan makna. Pengertian tangan yang menutupi wajah dengan badan dan anggota tubuh yang berkurang atau berkontraksi.

(6) Gerakan tari dapat dibedakan berdasarkan volume geraknya, yang dibedakan menjadi tiga, yaitu volume besar, sedang dan kecil. atau volume terbuka bersifat lakilaki, volume kecil atau volume tertutup bersifat feminin, dan volume medium memberikan kesan halus kejantanan dan feminitas.

(7) Gerak lebih berhati-hati terhadap pola gerak yang masing-masing memiliki karakternya sendiri-sendiri. Gerakan berpola datar memiliki karakter / karakter; terbuka, jujur, tetapi juga dangkal / sederhana.

(8) Gerakan berpola vertikal bersifat egosentris dan sangat cocok untuk mengekspresikan kepasrahan.

(9) Gerakan berpola horizontal memiliki keunggulan eling ingin pergi.

(10) Gerak berpola silang memberi kesan kuat tapi juga kesan bingung.

(11) Gerakan berpola murni, tidak satu pun bagian tubuh melintang yang bersifat tenang dan terbuka.

(12) Pola gerak melengkung yang manis.

(13) Gerakan yang ditepuk lurus atau siku memberi kesan yang kuat.

Nilai-Nilai di Balik Tarian Daerah Jawa

\begin{tabular}{|c|c|c|c|}
\hline No & Tarian Lokal & Deskripsi & $\begin{array}{ll}\text { Nilai } & \text { Pendidikan } \\
\text { Karakter } & \end{array}$ \\
\hline 1. & & $\begin{array}{l}\text { Bedhaya Ketawang terdiri dari } \\
\text { kata Ketaatan dan Ketawang. } \\
\text { Bedhaya berarti kesetiaan wanita } \\
\text { kepada penari di istana. } \\
\text { Ketawang berasal dari Raja / }\end{array}$ & $\begin{array}{l}\text { 1. ketaatan dan kesetiaan } \\
\text { kepada raja/pemimpin } \\
2 \text { 2. Tarian ini } \\
\text { mengembangkan rasa } \\
\text { cinta yang sangat kental }\end{array}$ \\
\hline
\end{tabular}




\begin{tabular}{|c|c|c|c|}
\hline & & $\begin{array}{l}\text { pemimpin. kata 'Tawang' yang } \\
\text { artinya bintang di langit. Tari } \\
\text { Bedhaya dan Ketawang } \\
\text { dianggap suci. Tarian satu tahun } \\
\text { ini diperagakan oleh sembilan } \\
\text { perempuan generasi Jawa yang } \\
\text { tetap seperti pengantin rnaup. } \\
\text { Sembilan orang memiliki } \\
\text { kepercayaan mereka sendiri } \\
\text { pada seni sebutan daerah: Batak, } \\
\text { Endhel Ajeg, Endhel Weton, Apit } \\
\text { Ngarep, Apit Mburi, Apit Meneg, } \\
\text { Gulu, Dhada, dan Boncit. } \\
\text { Angka Sembilan juga dapat } \\
\text { direpresentasikan sebagai } \\
\text { konstelasi bintang dari makna } \\
\text { Ketawang. Bedhaya Ketawang } \\
\text { adalah tarian ciptaan raja ketiga } \\
\text { Mataram, Sultan Agung (1613- } \\
\text { 1646) dengan mitos percintaan } \\
\text { antara raja pertama Mataram, } \\
\text { Panembahan Senopati, dengan } \\
\text { dewi Laut Selatan yang bernama } \\
\text { Ratu Kencanasari atau biasa } \\
\text { dipanggil Kanjeng Ratu Kidul- } \\
\text { tenn di kalangan masyarakat } \\
\text { Jawa Musik pengiring tarian ini } \\
\text { terdiri dari lima alat musik, yaitu } \\
\text { Kemanak, Kethuk, Kenong, } \\
\text { Kendhang, dan Gong yang } \\
\text { diiringi oleh suara orang Sinden. }\end{array}$ & $\begin{array}{l}\text { dengan budaya jawa dan } \\
\text { terhadap sesama. } \\
\text { 3. Mengajarkan kepada } \\
\text { generasi berikutnya tari } \\
\text { yang merupakan budaya } \\
\text { yang akan terus } \\
\text { dilestarikan. }\end{array}$ \\
\hline 2. & Tari Serimpi & $\begin{array}{l}\text { Tari Serimpi sudah ada sejak } \\
\text { Prabu Amiluhur pada saat masuk } \\
\text { ke Kerajaan Kraton mendapat } \\
\text { perhatian. } \\
\text { Tarian yang disarikan } 4 \text { Putri } \\
\text { masing-masing memiliki nama: } \\
\text { Air, Api, Angin dan Bumi atau } \\
\text { tanah. } \\
\text { Susunan segi } \\
\text { melambangkan tiang Pendopo. } \\
\text { Nama peran tersebut adalah } \\
\text { Batak, Gulu, Dhada dan Buncit. } \\
\text { Layaknya Bedhaya, } \\
\text { Srimpipun sakral atau sakral yaitu } \\
\text { Srimpi Anglir Mendhung. Selain } \\
\text { itu karena durasi penyajian (60 } \\
\text { menit) maka untuk konsumsi saat } \\
\text { ini diadakan inovasi. } \\
\text { - Anglirmendhung Serimpi, tari } \\
\text { panjang sampai } 11 \text { menit }\end{array}$ & $\begin{array}{l}\text { 1. Pengajaran tentang } \\
\text { kesetiaan pada lingkungan } \\
\text { 2. Memuliakan Yang Ilahi } \\
\text { (Nilai2 Dewa pencipta } \\
\text { tanah, yang selain } \\
\text { melambangkan } \\
\text { kemunculan manusia juga } \\
\text { melambangkan empat } \\
\text { alam; arah angin, Api, } \\
\text { bumi) sudut-sudut angin.. }\end{array}$ \\
\hline
\end{tabular}




\begin{tabular}{|c|c|c|c|}
\hline & & $\begin{array}{l}\text { - Gondokusumo Serimpi, tari } \\
\text { panjang sampai } 15 \text { menit }\end{array}$ & \\
\hline 3 & $\begin{array}{l}\text { Tari } \\
\text { Gambyong }\end{array}$ & $\begin{array}{l}\text { Tari Gambyong Berasal dari tari } \\
\text { Glondrong yang diekstrak oleh } \\
\text { Nyi Mas Ajeng Gambyong. } \\
\text { Menara yang sangat indah } \\
\text { ditambah keindahan suara ibu } \\
\text { kota yang baik, dan akhirnya Nyi } \\
\text { Mas dipanggil oleh Keraton } \\
\text { Surakarta untuk menari di istana } \\
\text { sambil memberikan pelajaran } \\
\text { kepada putra-putrinya. Saya dari } \\
\text { kerendahan hati untuk tamu Raja. } \\
\text { Oleh Istana Tari diubah menjadi } \\
\text { tarian Gambyong. Keunikan dari } \\
\text { tarian ini terletak pada } \\
\text { gerakannya penari dengan irama } \\
\text { gending dan kendang dimainkan. } \\
\text { Gending yang selalu mengawali } \\
\text { tarian ini adalah Gending } \\
\text { Pangkur, sedangkan alat musik } \\
\text { yang dimainkan selain Kendang } \\
\text { antara lain Gender, Kempul, } \\
\text { Kenong, dan Gong. Selain } \\
\text { sebagai hiburan, tarian ini juga } \\
\text { sering diarak untuk menyambut } \\
\text { tamu dalam upacara peringatan } \\
\text { hari dan pernikahan. Fitur Tari: } \\
\text { Jumlah penari seorang putri atau } \\
\text { lebih, memakai kawat jahit. • } \\
\text { Tanpa baju tapi memakai } \\
\text { kemben atau bangkin - Tanpa } \\
\text { Jamang tapi memakai sanggul } \\
\text { atau gelung. }\end{array}$ & $\begin{array}{l}\text { 1. Mengajarkan } \\
\text { menghormati tamu. } \\
\text { 2. Selamat Datang dan } \\
\text { Sesaji } \\
\text { 3. Membawa kelembutan, } \\
\text { senyuman dan keramahan } \\
\text { pada tamu. }\end{array}$ \\
\hline 4 & Beksan & 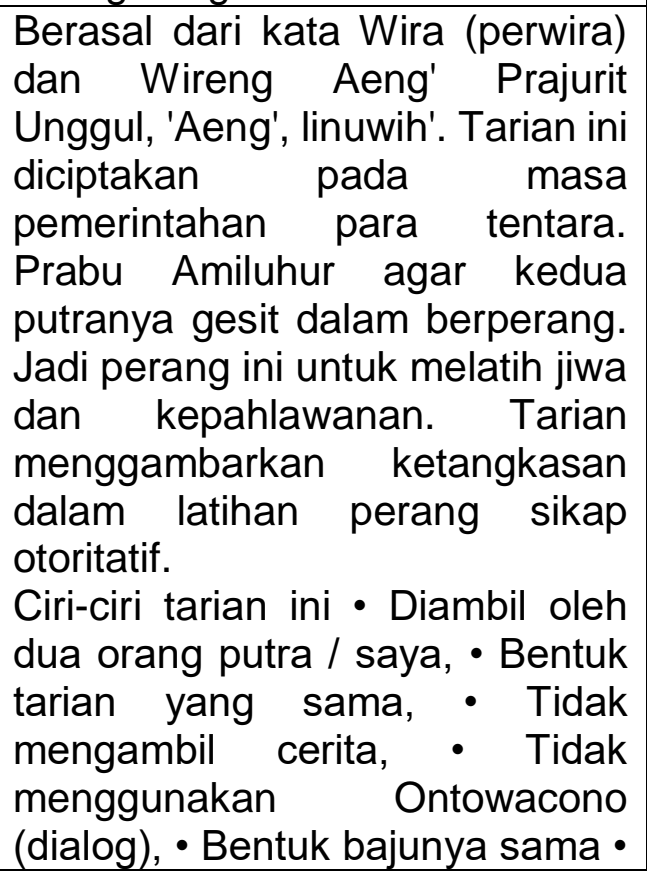 & $\begin{array}{lr}\text { '1. Sikap berani, } & \text { beranian } \\
\text { kehebatan dan keberanian } \\
\text { 2. Menanamkan } & \text { kepada } \\
\text { sang anak } & \text { dengan } \\
\text { menggunakan } & \text { senjata } \\
\text { perang } & \\
\text { 3. Tegas dan dengan } \\
\text { menggunakan } \\
\text { perang.. }\end{array}$ \\
\hline
\end{tabular}




\begin{tabular}{|c|c|c|c|}
\hline & & $\begin{array}{l}\text { Pertempurannya } \\
\text { Artinya tidak menganding, } \\
\text { gending till atau srepeg, hanya } \\
\text { irama atau tempo kendho atau } \\
\text { kencang. - Satu atau dua } \\
\text { gending, artinya kendang } \\
\text { tersebut kemudian diteruskan } \\
\text { dengan gendhing ketawang. } \\
\text { Tidak ada yang kalah atau } \\
\text { menang atau dies }\end{array}$ & \\
\hline 5. & $\begin{array}{l}\text { Tari } \\
\text { Bambangan } \\
\text { Cakil }\end{array}$ & $\begin{array}{l}\text { Merupakan tarian yang } \\
\text { mengandung nilai filosofi tinggi } \\
\text { dimana kejahatan, } \\
\text { kesombongan, kesombongan } \\
\text { dan sebagainya tidak ada artinya } \\
\text { karena akan dihancurkan oleh } \\
\text { kebaikan. Tarian ini menceritakan } \\
\text { perang antara Ksatria melawan } \\
\text { Raksasa. Ksatria adalah karakter } \\
\text { yang halus dan lembut, } \\
\text { sedangkan raksasa } \\
\text { menggambarkan sosok yang } \\
\text { kasar dan membawa sebagai } \\
\text { Perang antara Ksatria } \\
\text { (Bambangan) melawan ini } \\
\text { orang Cakil. Sangat Menarik, } \\
\text { Tarian ini merupakan (petikan) } \\
\text { murkaan / sifat jahat dan drama } \\
\text { rakyat, berawal dari } \\
\text { kesombongan Surakarta. (Giant } \\
\text { Cakil) yang diambil dari wiracarita } \\
\text { Mahabarata. Tarian ini } \\
\text { menggambarkan adegan perang } \\
\text { antara seorang ksatria Pandawa, } \\
\text { melawan Cakil (sosok raksasa). } \\
\text { Istilah Bambangan digunakan } \\
\text { untuk menggambarkan Ksatria } \\
\text { dari keluarga Pandawa, yang } \\
\text { dalam tariannya menggunakan } \\
\text { berbagai macam tarian halus } \\
\text { yang digunakan untuk kesatria } \\
\text { seperti Abimanyu, Sumitra dan } \\
\text { sebagainya. -Hanila - Prahasta. }\end{array}$ & $\begin{array}{l}\text { 1. Menunjukkan sikap dan } \\
\text { perilaku anak yang baik, } \\
\text { berani jujur, dari karakter } \\
\text { Bambangan (Arjuna). } \\
\text { 2. Menunjukkan pada } \\
\text { anak sikap dan perilaku } \\
\text { jahat } \\
\text { 3. Berani Melawan } \\
\text { Keangkara Raksasa } \\
\text { 4. Kemenangan atas pesta } \\
\text { yang jujur, kuat, berani, } \\
\text { dan sejati. }\end{array}$ \\
\hline 6. & Tari Bondan & $\begin{array}{l}\text { Tari Bondan Tarian ini } \\
\text { menggambarkan kasih sayang } \\
\text { seorang ibu Boneka mainan, } \\
\text { payung, guci, dan keceriaan bagi } \\
\text { si Anak Kecil sifat lainnya adalah } \\
\text { ciri khas tarian itu. Dulu } \\
\text { dibutuhkan di setiap desa di Solo. } \\
\text { Mengenakan kain Wiron, } \\
\text {-Memakai kesenangan dengan }\end{array}$ & $\begin{array}{l}\text { 1. Sikap kasih sayang } \\
\text { terhadap anaknya (Baby). } \\
\text { 2. Memiliki rasa tari } \\
\text { Bondan Cindogo dan } \\
\text { Mardisiwi merupakan } \\
\text { tanggung jawab bagi } \\
\text { tarian ceria yang lebih } \\
\text { muda, mengungkapkan }\end{array}$ \\
\hline
\end{tabular}




\begin{tabular}{|c|c|c|c|}
\hline & & 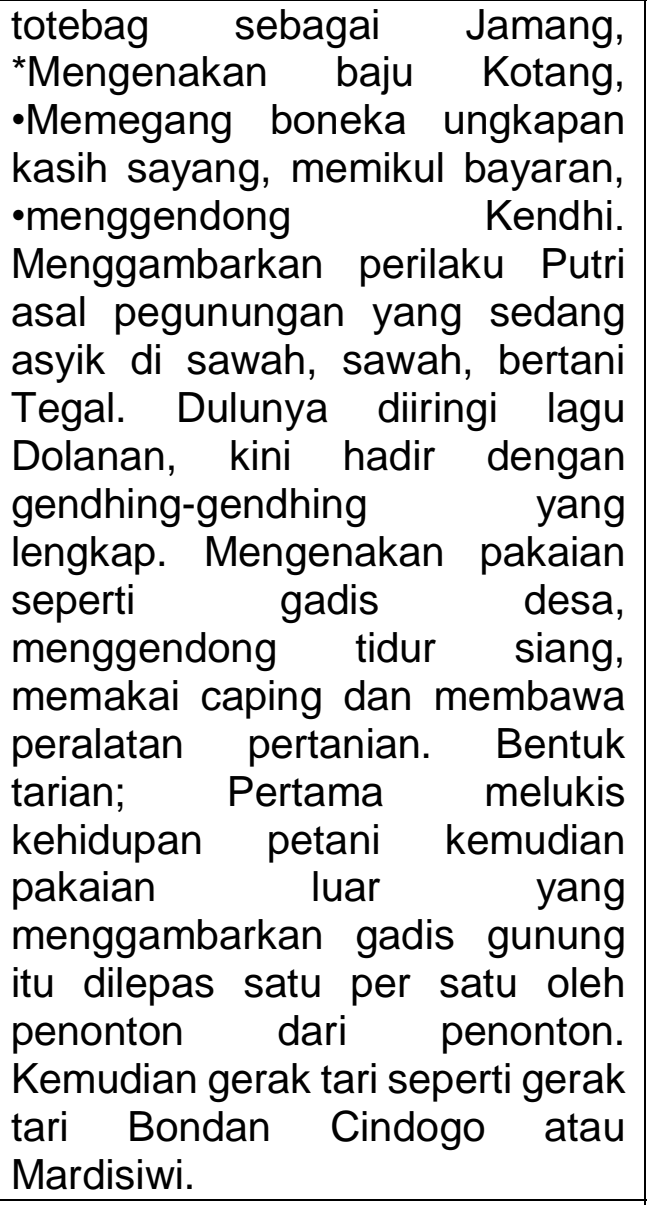 & $\begin{array}{l}\text { rasa iba terhadap adiknya } \\
\text { yang baru lahir. }\end{array}$ \\
\hline 7. & Tari Topeng & $\begin{array}{l}\text { Tarian ini sebenarnya berasal } \\
\text { dari Wayang Wong atau Drama. } \\
\text { Tari Topeng yang bermaksud } \\
\text { untuk tidak menunjukkan } \\
\text { kesuksesan yang dialami di } \\
\text { zaman Majapahit, membuat } \\
\text { kesan topeng yang terbuat dari } \\
\text { kayu yang dipoles dan } \\
\text { disungging sesuai dengan peran } \\
\text { tokoh / peran yang diambil dari } \\
\text { Wayang Gedhog, Menak Panji. } \\
\text { Tarian ini berkembang pesat } \\
\text { sejak Islam masuk dalam } \\
\text { kepercayaan Sunan Kalijaga } \\
\text { yang menggunakannya sebagai } \\
\text { spreadi agama. la menciptakan } 9 \\
\text { jenis topeng: Topeng Panji } \\
\text { Ksatrian, Condrokirono, Gunung } \\
\text { Sari, Handoko, Raton, Klono, } \\
\text { Denowo, Benco (TEMBEM). } \\
\text { Turas (Penthul). Pakaiannya dulu } \\
\text { memakai ikat kepala dengan } \\
\text { topeng yang diikatkan di } \\
\text { kepalanya. }\end{array}$ & $\begin{array}{l}\text { Menutup Wajah dengan } \\
\text { kesombongannya }\end{array}$ \\
\hline
\end{tabular}

Beberapa permainan tradisional Jawa yang dikaji dalam penelitian ini mengandung nilai edukatif. Hal ini sejalan dengan Jazuli (2015) yang mempelajari dan menemukan sistem 
nilai budaya yang tumbuh dan berkembang pada kelompok tari Prajuritan Kabupaten Semarang sebagai salah satu temuan penelitiannya. Senada juga dengan Setyaningrum, Asma, \& Indriyani (2018) yang melakukan penelitian untuk mengetahui nilai-nilai estetika dalam bentuk, isi, dan pementasan tari Gandaria di Kabupaten Rembang, Jawa Tengah, Indonesia. Salah satu hasilnya adalah konten tarian tersebut mengandung sebuah gagasan, suasana, dan pesan yang mengandung nilai-nilai kebersamaan, pergaulan, dan moralitas.

Penelitian ini juga menunjukkan bagaimana meningkatkan minat peserta didik dalam menari di tempat mereka berlatih menari di akhir pekan. Hal ini sejalan dengan Rosmiati (2018) yang mengkaji bagaimana strategi pembelajaran dalam pembinaan karakter nasionalis dengan menggunakan nyanyian dan tari tradisional dan salah satu hasilnya adalah tarian tarian nasional dilakukan di luar jam sekolah. Selain itu, memberdayakan para pembelajar untuk mengemas ulang tari tradisional bermanfaat untuk memunculkan kreatifitas, cerdas, aktif dan kreatif. Hal ini sejalan dengan Giyartini (2018) yang melibatkan siswa dengan mendesain ulang kemasan tari kreatif berbasis permainan tradisional tanpa meninggalkan nilai-nilai sehingga dapat meningkatkan kecerdasan dan kreativitas anak.

Peran siswa dalam penelitian ini adalah berlatih menari di dalam dan di luar sanggar tari. Inside artinya menari di sanggar untuk latihan menari dan pelajarannya. Di luar artinya memenuhi undangan menari di luar sanggar, yaitu menari di hari kemerdekaan Indonesia di kampus. Itu sejalan dengan. (Dewi, 2018) yang melakukan penelitian untuk mengungkapkan tradisi panji (Tari Jaranan dan Wayang Timplong) dalam seni pertunjukan di Jawa Timur dan berusaha mengungkap gerak tari yang berfungsi sebagai hiburan, bukan upacara lagi, meskipun Wayang Timplong masih memiliki fungsi dalam upacara. Para siswa tari menggunakan media sosial untuk berbagi latihan menari mereka untuk mempromosikan latihan dan pengalaman mereka; Oleh karena itu mereka mendapat tawaran untuk menari di luar sanggar tari. Mereka menari pada perayaan hari kemerdekaan Indonesia, misalnya, dapat meningkatkan pengalaman dan melatih bakat menari untuk melestarikan warisan budaya daerah. Hal ini sejalan dengan Hermino \& Arifin (2020) yang menyatakan bahwa media sosial dapat digunakan oleh semua orang untuk mengakses segala jenis informasi dan mempengaruhi pola hubungan dan komunikasi.

\section{KESIMPULAN}

Pendidikan karakter dalam permainan tradisional Jawa dapat dilihat dari pergerakannya, implementasinya dalam masyarakat dan kerjasama dengan institusi. Dengan mengidentifikasi pendidikan karakter dalam berbagai tari tradisional Jawa, menganalisis kebutuhan, keluaran, masalah, dan tujuan pembelajaran sekolah ramah anak (SLA) dalam melaksanakan pendidikan karakter berbasis tari daerah, (3) mengidentifikasi jenis nilai-nilai tari tradisional Jawa, siswa dan pelatih tari mendapatkan nilai-nilai pendidikan karakter untuk diajarkan kepada siswa guna memperkuat karakternya;: (1) Penerapan berbagai klen tradisional Jawa yang tidak diketahui (lokal) dari pinggiran kota dapat dilakukan untuk studi lebih lanjut guna menggali nilai-nilai, implementasi, dan dampaknya bagi siswa dan tari. sendiri, (2) meningkatkan jumlah pertemuan dalam latihan menari, tidak hanya setiap bulan, bermanfaat untuk meningkatkan kemampuan menari siswa lebih cepat; Oleh karena itu studi lanjut harus fokus pada alokasi waktu dalam berlatih menari, dan (3) meningkatkan kuantitas dan kualitas kerjasama dengan institusi formal dan informal untuk meningkatkan pengalaman peserta didik dapat dilakukan untuk studi lebih lanjut karena siswa yang lebih berpengalaman dalam menari meningkatkan kualitasnya. 


\section{REFERENCES}

Alfianti, D. A., Pratiwi, R. A., \& Suyatno.(2019). 9th International Conference on Physics and Its Applications (ICOPIA). In Study of stage acoustic parameters of Cak Durasim concert hall

Surabaya/orjavanese traditional dance performance (Vol. 1153, pp. 17). https://doi .org/10.1088/1742-6596/1153/1/012007

Ambarwangi, S., \& Suharto, S. (2014). Reog As Means of Students' Appreciation and Creation in Arts and Culture Based on the Local Wisdom. Harmonia: Journal of Ans Research and Education, 14(1), 37-45. https://doi.org/10.15294/harmonia.v 14i 1.2789

Ardhiani, Y. D. (2016). Sahita's Performance,Satire of the Life ofJavanese Women.

International Journal of Creative and Arts Studies,

3(2), 63-72. https://doi.org/10.24821/ijcas.v3i2. I 846

Arjo, I. D. (1989). Women's Dance Among the Sundanese of West Java, Indonesia. Asian

Theatre Journal, 6(2), 168-178. Retrieved from http://www.jstor.org/stable/1124458

Christensen, P. (2013). Modernity and Spirit Possession in Java -

Horse Dance as a Threatened Space of Interpretation.

Competence Network DOR/SEA-Dynamics of Religion in

Southeast Asia, (2), 1-14. Retrieved from

https://www.researchgate.net/publication/31 1775875\%0AModernity

Denok, M., Jazuli, M., Rohindi, T., \& Suminto, S. (2018). Advances in

Social Science, Education and Humanities Research (ASSEHR), volume 247 International Conference on Science and Education and Technology 2018 (ISET 2018) The. In The Strengthening Of Humanity Value in The Generation of Digital Natives in the Era Of Digital Technology Through NawungSekar Dance (Vol. 247, pp. 329-333). htrps://doi.org/ 10.2991/iset-I 8.2018.68

Dewi, T. K. S.(2018). Panji Tradition in the Jaranan Jor and Wayang Timplong Performance Arts in East Java. /SLLAC: Journal of Intensive Studies on language, Literature, Art, and Culture, 2(2), 13-20. hrrps://doi.org/lO.I 7977/um006v2i22018p013

Giyartini, R.(2018). Development of Child Education Tourism through Creative Dance in West Java-based Traditional Games. In Advances in Social Science, Education and Humanities Research, volume 231 5th International Conferenceon Community Development (AMCA 2018) (Vol. 231, pp. 91-93). Atlantis Press.

https://doi.org/ 10.2991/amca-18.2018 .26 Hermino, A., \& Arifin, I. (2020). Contextual Character Education for Students in the Senior High School. European Journal of Educational Research, 9(3), 1009-1023. https://doi.org/ 10.12973/eu-jer.9 .3. 1009

Irianto, A. M. (2016). The Development of Jathilan Performance as an Adaptive Strategy

Used by Javanese Farmers. Harmonia: Journal of Arts Research and Education, 16(I),

38-48. https://doi.org/10.15294/harmonia.v $\quad$ | 611.5213 
JazuJi, M.(2015). Aesthetics of Prajuritan Dance in Semarang

Regency. Harmonia: Journal of Arts Research and Education., 15(I), 16-24.

https://doi.org/ 10.15294/harmonia.v I5i 1.3692

Kusnadi, Ardhana, W., Setyosari, P., \& Efendi, M. (2017). THE

EFFECT OF EXPERIENTIAL LEARNING STRATEGIES TO

STUDENTS' APPRECIATION OF

106-114.

Retrieved from www.journaJs.savap.org.pk

Malarsih, M.(2016). The Tryout of Dance Teaching Media in Public

School in The Context of Appreciation and Creation Learning.

Harmonia: Journal of Arts Research and Education, 16(1), 95.

https://doi.org/10.15294/harmonia.v | $6 \mathrm{i} 1.4561$

Marsim, A. N., Mulyanto, \& Sudiyanto.(2019). Tuping Dance Learning at

SMA Negeri 2

Kalianda South Lampung. In Advances in Social Science, Education and

Humanities

Research, volume 421 4th InternationalCon ferenceon Arts Language and

Culture

(/CALC 2019) Tuping (Vol. 421, pp. 15-20).

https://doi.org/ 10.2991/assehr .k.200323 .003

MeinaJ, T. R., \& Rahmawati, R. (2016). The Srimpi Renggowati: A

Study of Sustainable Cultural Tourism in The Art of Classical

Javanese Dance in Yogyakarta. In The Srimpi Renggowati: A

Study of Sustainable Cultural Tourism in The Art of Classical Javanese

Dance in Yogyakarta(pp. 427-431). https://doi.org/10.2991/atf-

16.2016 .65

Nurindiyani, A., Pramadihanto, D., \& Afifah, R.(2019). 2019 International Electronics Symposium (JES) Motion. In Motion Modelingof TraditionalJavanese Dance: Introduction of Javanese Dancer Gesture with JD Models (pp. 195-20 I). LEEE.

Okado, K. (2011). When Women are Kings: Cross-Gendered Expression in an AllFemale

Central Javanese Court Dance-Drama and Its Public Reception. UrbanScope, 2, 19-30.

Rapoport, E.(2018). Jathilan Horse Dance: Spirit Possession Beliefs and Practices in The Present-Day Java. JKAT: The IndonesianJournal of Southeast Asian Studies, 2(1 ), 1-17.

https://doi.org/ 10.22146/ikat.v2i 1.37389

Rosmiati, S. H. (2018). DEVELOPING THE NATIONALISM

CHARACTER OF YOUNG LEARNERS BY USING SONGS

AND TRADITIONAL DANCES OF INDONESIA. In Proceedings of

the International Conference on the Roles of Parents in Shaping

Children's Characters (ICECED), December 3-4, 2018, AnjongMon Mata, Banda

Aceh,

Indonesia (pp. 287-292).

Saputra, R. G. C., Supriyadi, \& Demartoto, A.(2019). International 
Journal of Education and Social Science Research. International Journal of Education and Social Science Research, 2(2), 97-115.

Retrieved from http://ijessr.com

Sawitri, Sudardi, B., Abdullah, W., \& Chaya, N.(2016). Innovations in Bedhaya Dance in the

Age of Globalization. Journal of Education and Social Sciences, 5(2), 318-323.

Setyaningrum, H., Asma, M. U., \& Indriyani, P. D. (2018). Advances in Social Science, Education and Humanities Research, volume 276 2nd International Conference on Arts d Culture (ICON ARC 2018). In Aesthetic Review of Gandaria Dance Show in Rembang Regency (Vol. 276, pp. 39-43). https://doi.org/l0.2991/iconarc-18.2019.64

Shoji, M., Takafuji, Y., \& Harada, T. (2020). Behavioral impact of disaster education: Evidence from a dance-based program in Indonesia. International Journal of Disaster Risk Reduction, 45(August 2019), 113.https://doi.org/10.1016/j.ijdrr.2020.101489

Slamet. (2019). The Development of Jaranan Temanggungan as Indonesian Intangible

Heritage. Arts and Design Studies, 77, 45-54. https:1/doi .org/10.7176/ads/77-06

Supeni, S., Nurati, D. E., Sufa, F. F., \& Jumintono. (2019). Character education development model based on regional culture. Journal of Advanced Research in Dynamical and Control Systems, 11(5 Special Issue), 673-683.

Sutyasadi, P., \& Suharti, T.(2010). Implementation of interactive computer aided instruction

in learning of Javanese traditional classic dance. World Academy of Science, Engineering and Technology. International Journal of Mechanical and Mechatronics Engineering, 4(6), 503-507.

Wessing, R. (1999). A Dance of Life: The Seblang of Banyuwangi, Indonesia. Royal Netherlands Institute of Southeast Asian and Caribbean Studies, 155(4), 644-682. Retrieved from http:1/www .jstor.org/stable/27865557

Wisang, A.M.(2019). Cultural Co-Modification of Jaranan Turangga Yakso Dance in Jaranan Festival Intrenggalek Region. Journal of Advances in Social Science and Humanities, 5(1 ), 555-561. https//doi .org/10. 15520/jassh51394 